\title{
Markets, Economics, and the Role of Extractive Metallurgists
}

\section{Boyd Davis and Luisa Moreno}

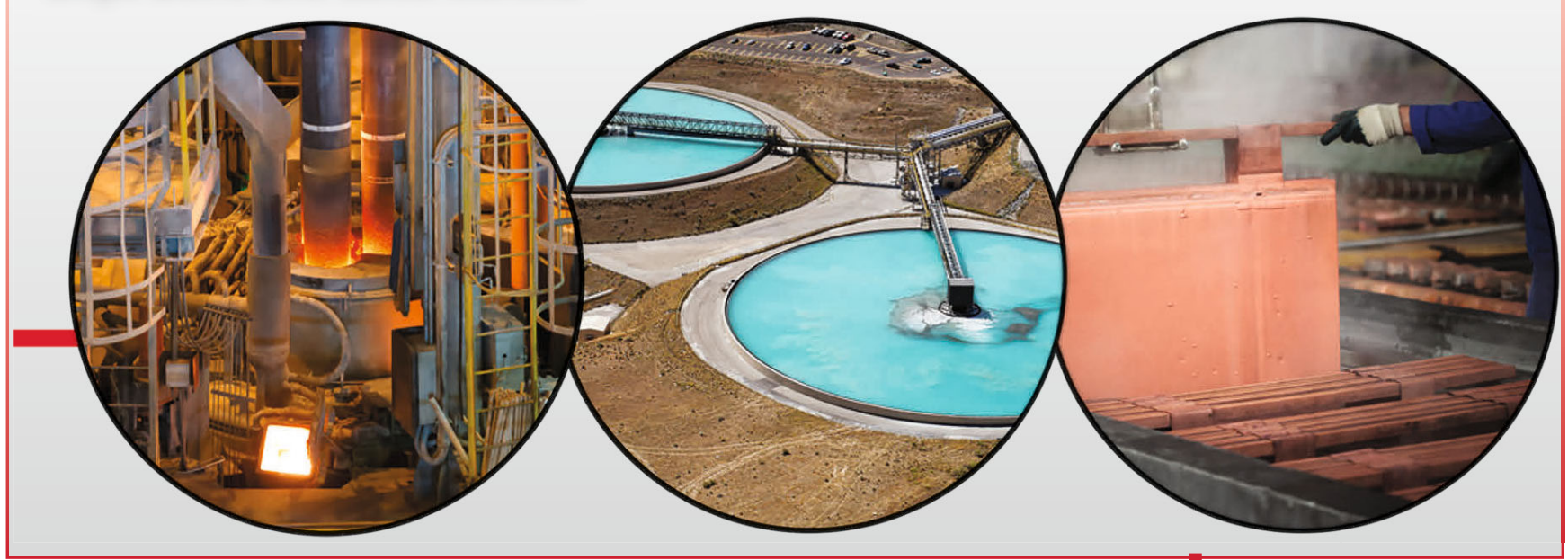

It is quite easy for members of our profession to be immersed in the technical content at conferences - after all, there are always some not-to-be missed presentations at these events. However, it is important to keep the bigger picture in mind - that technology must be integrated

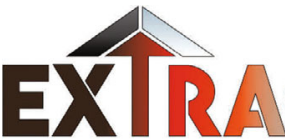

0002018

Registration Open for Extraction 2018

\section{August 26-29, 2018 Westin Ottawa, Ottawa, Ontario, Canada}

Don't miss Extraction 2018-a new opportunity to gather with your colleagues in the global extractive metallurgy community. Register before June 26 to take advantage of discount rates. Please note that the housing registration deadline is July 24.

Visit www.extractionmeeting.org for additional information and to register. into economics and that an understanding of the markets is critical to bringing new commodity sources into operation.

As extractive metallurgists, it is incumbent on us to help educate those in the financial sector, as well as geologists and miners, about the key role that early analysis of a project's processing component can play in the success of that project. It is also useful for us to better understand the financial drivers that often run in parallel, but not always in step, with downstream technology. What we see as exciting innovations in process development are often seen by the financial community as highly risky technological leaps with the potential of massive capital and operating cost overruns. (Sadly, there are a number of examples of this.)

Mining project development is a timely topic. The project development slump of the last five years is coming to an end and there is renewed interest in mining projects, as a resurgence in global growth continues to drive increased requirements for new sources of supply. The demand for battery materials to supply the massive growth expected in electric vehicles has also renewed interest and is opening up massive demand growth for certain minor metals and materials, often referred to as strategic materials. The development of lithium,

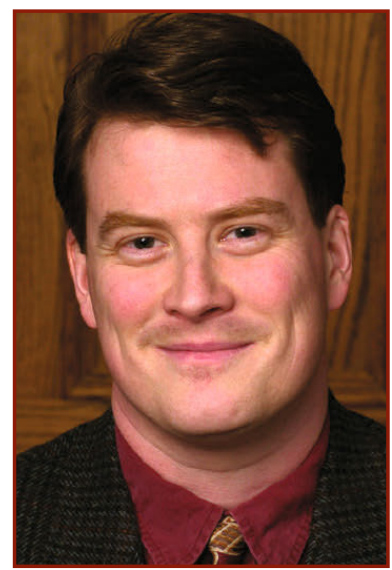

Boyd Davis

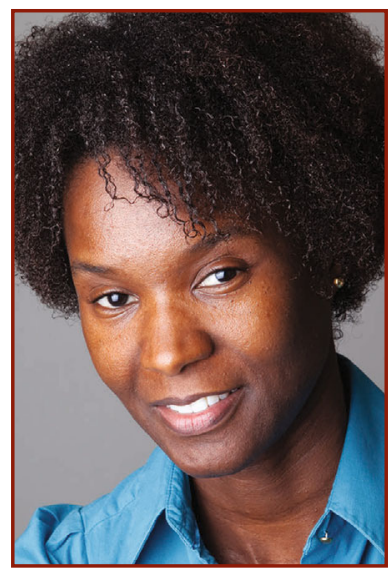

Luisa Moreno 
graphite, and cobalt deposits, to name some of the strategic materials, is not the same as for copper-gold deposits. A broader understanding of processing is needed with these resources to be sure that they can be economically brought to market-it involves more than just the deposit grade or size.

For all metals, companies are turning to more complex ores - the "easy" projects always get developed first, which means the remaining projects are inherently more politically and technically challenging. This means that the role of the extractive metallurgist is even more crucial to the overall arch of a project, and the financial and technical worlds must start to interact in a more meaningful way.

As part of Extraction 2018, slated for August 26-29 in Ottawa, Ontario, Canada, a number of speakers have been invited to give attendees a primer on the world of resource finance in the symposium, Markets and Economics. The symposium will be held from 1:00 p.m. to 4:00 p.m. on Sunday, August 26, with the technical portion of the conference starting on Monday.

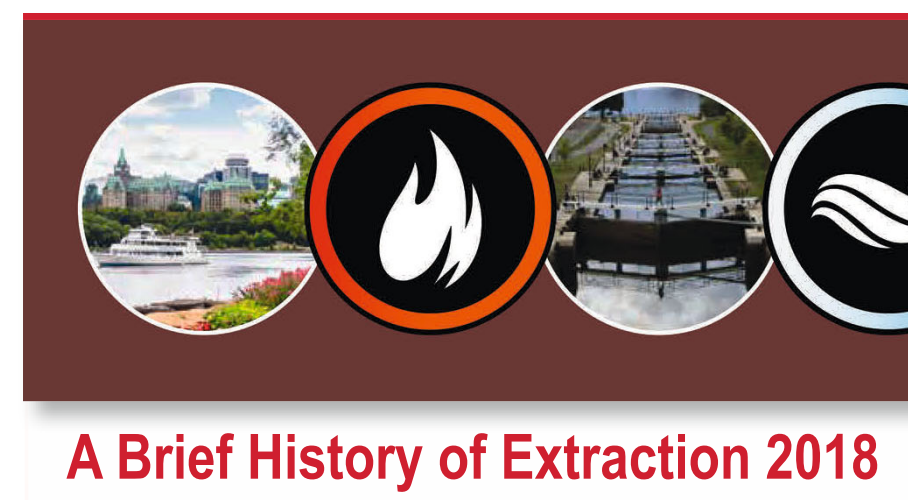
Boyd Davis

Extraction 2018 came about after a number of members of NAEMC (North American Extractive Metallurgy Committee, which oversees interaction among the Metallurgy and Materials Society (MetSoc) of the Canadian Institute of Mining, Metallurgy and Petroleum (CIM), the Society for Mining, Metallurgy \& Exploration (SME), and The Minerals, Metals \& Materials Society (TMS)) realized that there was going to be at least four extractive metallurgy conferences planned for 2018 . Bringing them all under one roof for maximum convenience and impact on behalf seemed like the right thing to do.

A key catalyst for the development of Extraction 2018 was the inclusion of Hydrometallurgy 2018, a revolving hydrometallurgy conference that runs every four years among MetSoc, SME, and TMS. In addition, TMS's highly regarded Sulfide Smelting Symposium that occurs every six years has been brought to Extraction 2018. These two anchoring symposia are supported by SME with its symposium on Sulfide Flotation. The extractive sections of MetSoc (Pyromet and Hydromet) are contributing significantly to the Extraction 2018 program as well, with the MetSoc Pyromet section assisting with the Peter Hayes Symposium and the MetSoc Hydromet section running the Gordon

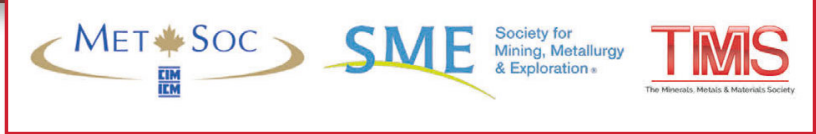

Ritcey Symposium as part of Hydrometallurgy 2018.

In addition, an all-conference plenary is planned for Sunday, August 26, at 4:00 p.m., immediately following the Markets and Economics symposium previewed in the main article. The plenary will give attendees a look at where the industry has come from and where it is going from two experts, Jeremy Mouat and Peter Warrian, who combine their knowledge of history and technology in the extractive sector to set the stage for a deeper perspective for the technical programming that will run from Monday, August 27, to Wednesday, August 29. The three societies have a number of other events planned as well, including poster sessions, short courses, an industrial exhibition, tours, and networking and social opportunities.

Extraction 2018 marks the first time that SME, TMS, and MetSoc have all jointly organized a conference. So far, it has been an excellent experience for members of the three societies who meet on a monthly basis to discuss the progress of the meeting. Each society is contributing to make the conference a success, and based on the number of papers accepted and the response so far, it looks like we will have an excellent turnout of professionals from around the world. 
The presentations will roughly follow the path of a mining project. The lead-off speaker, Mark Selby, is president of RNC Minerals, which is currently developing one of the largest nickel reserves in the world with the Dumont Project in Canada. He will begin the symposium with a discussion on the world of junior mining, how junior mining companies operate, and what is important to them. There will be special attention to how companies interact with technology —an important issue, since many junior companies have a higher risk tolerance than producing companies.

Bankers and investors are really key to project financing, and they are brought in at various stages of mine development so that mining projects can have access to sufficient capital to advance through each stage. Information must be clearly presented to them and processed in a way that minimizes risk while maximizing the opportunity. Raising money involves not just determining "how much" capital will be required to reach the next stage, but also "how" the capital will be raised (i.e., equity or debt), "from whom," and "under what terms." Nothing can move forward without the cash to pay for it.

Research analysts on both the sell side (investment banks) and buy side (investment funds) play an important role. Analysts try to cover both the financial and technical aspects of a project. They interact with companies to help get the word out about their project (sell side) through research reports. Others work for funds that buy shares in these companies (buy side). The marriage between the financial sector and technical sector is an important part of an analyst's job.

This is why a key aspect of the Extraction 2018 Markets and Economics symposium is discussion on how companies are promoted, the basis for their share valuation, and what investors look for when choosing companies. It should be an eye-opening experience for those of us who think of technology as the main driver for company valuation.

As projects advance, they go from initial bench scale, to pilots, to demonstrations. This chain of technical work needs to advance the project in the right way. Often the financial path and the technical path end up out of sync, causing disruptions on both sides. A highlight of the Markets and Economics symposium will be a presentation by Michael Samis from Ernst \& Young that will look at piloting from the financial side - what aspects are key to a project successfully moving forward.

Once a project is ready to go with a complete bankable feasibility study, the full project mining finance package needs to be put together - capital costs can run from a few million to billions of dollars and can involve multiple investments groups, such as private equity funds and end-users, each with different risk tolerances and capital return requirements.

At the end, once the resource is extracted, it has to be sold. This is relatively straightforward for clean, London Metal Exchange (LME) traded materials, but much more complicated for concentrates, secondary materials, and non-LME resources. Jay Hemenway, of Ocean Partners will give a revealing talk at the symposium on the world of commodity trading. Hemenway is an extractive metallurgist turned trader and will specifically discuss how extractive metallurgists who operate on projects and technologies that have timelines of perhaps a decade can be better informed by traders who operate on timelines of days.

Lastly, as a part of a global industry, it is important to understand how China fits into the equation. Extraction 2018 is fortunate to have Suping Yao, a Chinese Master of Design for non-ferrous metals with China Nerin Engineering Company, close the Markets and Economics symposium with a talk on how Chinese smelters operate and the factors affecting their profitability.

The Markets and Economics symposium is shaping up to be an interesting and educational start to Extraction 2018. Hopefully, it will make a lasting impression on attendees, while they discuss flotation, leaching, and smelting over the course of the conference.

Boyd Davis is principal, Kingston Process Metallurgy, Inc., and a conference co-chair of Extraction 2018. Luisa Moreno is a managing partner and analyst with Tahuti Global and a co-organizer and featured speaker at the Markets and Economics symposium at Extraction 2018.
"It is important to

keep the bigger

picture in

mind-that

technology must

be integrated

into economics

and that an

understanding

of the markets

is critical to

bringing new commodity

sources into

operation." 